UDC 631.153 .3

\title{
Effect of tillage on productivity of crop rotation and nitrate contain in topsoil under unstable of atmospheric precipitation
}

\section{Ya.A. Pogromska}

NSC “Institute for Soil Science and Agrochemistry Research named after O.N. Sokolovsky”, Kharkiv, Ukraine

\begin{tabular}{|c|c|}
\hline ARTICLE INFO & ABSTRACT \\
\hline $\begin{array}{l}\text { Received } 25.12 .2018 \\
\text { Received in revised } \\
\text { form } 07.05 .2019 \\
\text { Accepted } 19.08 .2019 \\
\text { Available online } \\
01.09 .2019\end{array}$ & $\begin{array}{l}\text { The aim of the work was to identify the presence of a relationship between the productivity of } \\
\text { grain-row crop rotation and the content of nitrates in the topsoil with different ways of its main } \\
\text { tillage. Eight-year monitoring was conducted within a long stationary field experiment on the } \\
\text { territory of the experimental farm of NSC ISSAR in Donetsk region. The content of nitrate } \\
\text { nitrogen in chernozem ordinary was determined on three soil treatment options - moldboard } \\
\text { ploughing, subsurface non-turning soil tillage and no-till. At the same time, the dynamics of } \\
\text { weather conditions was observed and the hydrothermal coefficient of Selianinov (HTC) was }\end{array}$ \\
\hline $\begin{array}{l}\text { Keywords: } \\
\text { crop yield; } \\
\text { nitrates; } \\
\text { no-till; } \\
\text { plowing; } \\
\text { Selianinov } \\
\text { hydrothermal } \\
\text { coefficient; } \\
\text { subsurface tillage. }\end{array}$ & $\begin{array}{l}\text { analysis in a sample of the results of } 729 \text { individual observations. It is shown that after a two- } \\
\text { year drought, an increase in yield occurs along with an increase in the content of nitrates in } \\
\text { the soil on all variants of soil treatment. However, a year after the overmoistening, the yield } \\
\text { decreases, despite the still high level of nitrate nutrition. In years with critically low humidity, } \\
\text { the greatest yields are recorded on moldboard plowing. By comparing the treatment efficiency } \\
\text { without soil turnover and the conventional moldboard plowing, we determined the conditions } \\
\text { under which minimization of tillage is advisable. With an increase in the degree of } \\
\text { minimization of tillage, the positive peak on the graph of the relative yields dynamics } \\
\text { decreases and the negative one deepens. With no-till, the productivity of crops decreases in } \\
\text { years with a HTC less than } 0.6 \text { at the same time as a decrease in the nitrate content in the } \\
\text { soil. For no-till, a positive correlation was also determined between the level of nitrate content } \\
\text { in the soil last year and the crop yield in the following. It was found that the non-use of plowing } \\
\text { increases the risk of negative effects of excessive soil moisture if the nitrate content is high. It } \\
\text { has been proven that a lack of nitrogen is not a factor in determining yields under subsurface } \\
\text { non-turning tillage. However, with no-till, the decrease in yield is due to a decrease in the } \\
\text { content of nitrate nitrogen in the soil, which has a long-term effect. Based on this, it is possible } \\
\text { to predict the effectiveness of the direct sowing system. The regression analysis determined } \\
\text { the dependence of the relative yield for no-till on the relative content of nitrates in the soil of } \\
\text { the previous year ( } r=0.950) \text {. }\end{array}$ \\
\hline
\end{tabular}

*E-mail: joanap@i.ua

Citing: Pogromska Ya.A. 2019. Effect of tillage on productivity of crop rotation and nitrate contain in topsoil under unstable of atmospheric precipitation. Agrochemistry and Soil Science. Collected papers. No. $88 . \quad$ ISSAR. Kharkiv. P. 95-100. DOI: https://doi.org/10.31073/acss88-13 (Ukrainian).

\section{References}

1. Lohinova I.V. Prediction of the effectiveness of fertilizers for corn grain according to soil diagnostics. Naukovi dopovidi NUBiP/ 2012. 3 (32). URL: http://nd.nubip.edu.ua/2012_3/12liv.pdf. (Ukr.).

2. Binford G.D. 1992. Relationships between cornyields and soil nitrate in late spring. Agron. J. Vol. 84. P. 53-59.

3. Khusainov A.T., Seydalina K.Kh. 2009. Nitrate nitrogen content in black soil in Northern Kazakhstan. Bulletin of the Altai State Agrarian University. № 3 (53). P. 27-30. (Rus.).

4. Akimova O.I. 2013. The effect of nitrogen nutrition on the yield of winter rye grain. Bulletin of the Altai State Agrarian University. № 8. P. 13-18. (Rus.).

5. Mengel D., Asebedo R. 2014. Correlation of soil test nitrate level, N rates, and wheat yields. Agronomy eUpdate. Issue 468 August 1st, 2014. URL: https://webapp.agron.ksu.edu/agr_social/m_eu_article.throck?article_id=295.

6. Barker A.V., Pilbeam D.J. 2015. Handbook of Plant Nutrition. 2nd Edition. CRC Press. 2015. 773 pp.

7. Balayev A.D., Tonkha O.L. 2018. Soil Fertility, its Species and the Restoration of Modern Cultivation Technologies. Agrochemistry and Soil Science. Special issue for the XI Congress of Soil Scientists and Agrochemicals of Ukraine (September 17-21, 2018, Kharkiv). Book 1. Soil Science. Kharkiv. P. 114-123. (Ukr.).

8. Balayev A.D., Gavrilyuk M.V. 2018. Restoration of fertility of chernozem for soil protection agriculture. Agrochemistry and Soil science. Special issue for the XI Congress of Soil Scientists and Agrochemicals of Ukraine (September 17-21, 2018, Kharkiv). Book 1. Soil Science. Kharkiv. P. 123-125. (Ukr.).

9. Adaptation of agrotechnologies to climate change: soil and agrochemical aspects: collective monograph. NSC "Institute of Soil Science and Agrochemistry named after O. N. Sokolovsky". Kharkiv. Stylna typografiia, 2018. 364 p.

10. Pikovska O.V. 2013. Characteristics of the nitrogen regime of chernozem ordinary in different tillage systems. Bulletin of Kharkiv National Agrarian University. Series: Soil Science, Agrochemistry, Agriculture, Forestry. No. 1. P. 6567. (Ukr.).

11. Triduh Ye.I., Radziyevsky L.L, Cheryachukin M.I, Shymansky Yu.P. et.al. 1994. Effect of tillage and fertilizer on productivity of corn in the conditions of northern Steppe of Ukraine. Stepove zemlerobstvo. Kyiv: Urozhay, Iss. 28. P. 46-50. (Ukr.).

12. Strelchuk A.Ya. 1991. The effectiveness of minimizing the treatment of chernozem leached under winter wheat 
after maize for silage in the conditions of the south-western Forest-Steppe of the Ukrainian SSR: the dissertation author's abstract on the degree of a Ph.D. in Agricultural Sciences : 06.01.01, Kamenets Podilskyi. 17 p. (Rus.).

13. Tsiuk O.A. 2011. Formation of the nutrient regime of chernozem typical in farming systems. The Bulletin of Kharkiv National Agrarian University. № 2. P. 140-144. (Ukr.).

14. Davydenko V.V. 1999. Agrophysical properties, nutrient regime of the soil and corn yield depending on precursors, tillage and fertilizers. Bulletin of the Institute of Grain Farming of the UAAS. No. 10. P. 8-10. (Ukr.).

15. Bista P., Norton U., Ghimire R, Norton J.B.. 2017. Effects of tillage system on greenhouse gas fluxes and soil mineral nitrogen in wheat (Triticum aestivum, L.) - fallow during drought. Journal of Arid Environments. 147. P. $103-113$. DOI: 10.1016/j.jaridenv.2017.09.002.

16. Alhajj Ali S., Tedone L., Verdini L., Cazzato E., De Mastro G. 2019. Wheat Response to No-Tillage and Nitrogen Fertilization in a Long-Term Faba Bean-Based Rotation. Agronomy J. 9(2), 50. DOI: 10.3390/agronomy9020050.

17. Tsiliurik O.I. 2016. Efficiency of minimum soil tillage for corn under conditions of the Northern Steppe of Ukraine. News of Dnipropetrovsk State Agrarian and Economic University. No. 2. P. 5-9. (Ukr.).

18. Nascente A.S., Costa C.A., Cobucci C.T. 2012. Ammonium and nitrate in soil and up land rice yield as affected by cover crops and their desiccation time. Pesq. agropec. bras., Brasília, V.47, n.12, P.1699-1706.

19. Climatology. URL http://ggf.tsu.ru/content/faculty/structure/chair/meteorology/publications/Климатология/text/111.html.

20. Dordas C. 2009. Role of Nutrients in Controlling Plant Diseases in Sustainable Agriculture: A Review. In: Lichtfouse E., Navarrete M., Debaeke P., Véronique S., Alberola C. (eds) Sustainable Agriculture. Springer, Dordrecht. P. 443-460. DOI 10.1007/978-90-481-2666-8_28.

Удк 631.153.3

Вплив способу обробітку ґрунту на продуктивність сівозміни і вміст нітратів в орному шарі за нестабільності атмосферного зволоження

\section{Я.А. Погромська}

ННЦ «Інститут ґрунтознавства та агрохімії імені О.Н. Соколовського», Харків, Україна E-mail: joanap@i.ua

ІНФОРМАЦІЯ

Отримано 25.12.2018

Отримано після

доопрацювання

07.05.2019

Затверджено до друку

19.08.2019

Доступно онлайн

01.09 .2019

Ключові слова:

безвідвальний

плоскорізний обробіток;

гідротермічний

коефіцієнт Селянинова

$\Gamma T K$

нітрати;

нульовий обробіток

оранка;

урожайність культур.
АНОТАЦІЯ

Метою було виявити наявність зв'язку продуктивності зерно-просапної сівозміни та вмісту нітратів у ґрунті за різних способів його основного обробітку. В умовах польового досліду на території Донецької області впродовж 8 років проводили моніторинг вмісту нітратного азоту в орному шарі чорнозему звичайного на трьох варіантах обробітку ґрунту - оранки, безвідвального плоскорізного та нульового (поtill). Одночасно спостерігали динаміку погодних умов і розраховували гідротермічний коефріцієнт (ГТК). Статистичну обробку даних виконано кореляційним, регресійним та ANOVA аналізом у вибірці 729 індивідуальних спостережень. Показано, що на всіх варіантах після дворічної посухи відбувається збільшення врожаю на фоні підвищення вмісту нітратів у ґрунті, а через рік після перезволоження врожайність падає, незважаючи на високий рівень нітратного живлення. У критичні за зволоженням роки найбільші врожаї зафіксовано на оранці. Співставленням ефективності обробітків без обертання пласта і традиційної відвальної оранки визначено умови, за яких мінімізація обробітку ґрунту є доцільною. Із підвищенням ступеню мінімізації обробітку ґрунту зменшується додатний пік на графріку динаміки відносних врожаїв і поглиблюється від'ємний. Для no-till формується зниження продуктивності культур у роки із ГТК менше 0,6 на фоні зниження рівня нітратного живлення. Для нульового обробітку визначено позитивний корелятивний зв'язок між рівнем умісту нітратів у ґрунті минулого року і кількістю продукції наступного року. Виявлено, що відмова від обертання пласта посилює ризик негативних наслідків перезволоження за підвищеного рівня нітратів у ґрунті. Доведено, що нестача азоту не $€$ визначальним фрактором урожаю за безвідвального плоскорізного обробітку ґрунту. За no-till падіння врожайності обумовлюється тривалим зменшенням вмісту нітратного азоту в ґрунті, на підставі чого можливим є прогнозування ефективності системи прямого посіву. Регресійним аналізом визначено залежність відносної врожайності за no-till від відносного вмісту нітратів у ґрунті позаминулого року $(r=0,950)$.

E-mail: *kuzmishyna_s_@ukr.net; **pkboyko@ukr.net

Форма цитування: Погромська Я.А. Вплив способу обробітку ґрунту на продуктивність сівозміни і вміст нітратів в орному шарі за нестабільності атмосферного зволоження Асрохімія і грунтознавство. Міжвід. тем. наук. збірник. Вип. 88. Харків: ННЦ “ІГА ім. О.Н. Соколовського". 2019. C. 95-100. DOI: https://doi.org/10.31073/acss88-13.

Удк 631.153 .3

Влияние способа обработки почвы на продуктивность севооборота и содержание нитратов в пахотном слое при нестабильности атмосферного увлажнения

\section{Я.А. Погромская}

ГП ОХ «Донецкое» ННЦ «Институт почвоведения и агрохимии имени А.Н. Соколовского» Харьков, Украина E-mail: joanap@i.ua

Целью работы было выявление наличия связи между продуктивностью зерно-пропашного севооборота и содержанием нитратов в почве при различных способах ее основной обработки. В условиях полевого опыта на 
территории Донецкой области на протяжении 8 лет проводили мониторинг содержания нитратного азота в пахотном слое чернозема обыкновенного на трех вариантах обработки - вспашки, безотвальной плоскорезной и нулевой (no-till). Одновременно наблюдали динамику погодных условий и рассчитывали гидротермический коэффициент (ГТК). Статистическую обработку данных выполнили корреляционным, регрессионным и ANOVA анализом в выборке из результатов 729 индивидуальных наблюдений.

Показано, что на всех вариантах после двухлетней засухи происходит увеличение урожая на фоне повышения содержания нитратов в почве, а через год после переувлажнения урожайность падает, несмотря на высокий уровень нитратного питания. В критические по увлажнению годы наибольшие урожаи зафиксированы на вспашке.

Сопоставлением эффрективности обработок без оборота пласта с традиционной отвальной вспашкой определены условия, при которых минимизация обработки целесообразна. С повышением степени минимизации обработки почвы снижается положительный пик на графике динамики относительных урожаев и углубляется отрицательный. Для по-till формируется снижение продуктивности культур в годы с ГТК менее 0,6 на фоне снижения уровня содержания нитратов в почве. Для нулевой обработки также определена положительная корреляционная связь между уровнем содержания нитратов в почве в прошлом году и количеством продукции в следующем. Установили, что отказ от оборота пласта усиливает риск негативных последствий переувлажнения при повышенном уровне нитратов в почве. Доказано, что недостаток азота не является определяющим фактором урожая при безотвальной плоскорезной обработке почвы. Но при нулевой обработке падение урожайности обусловлено уменьшением содержания нитратного азота в почве, имеющим долговременный эффект, на основании чего возможно прогнозирование эффрективности системы прямого посева. Регрессионным анализом установлена зависимость относительной урожайности при по-till от относительного содержания нитратов в почве в позапрошлом году $(r=0,950)$.

Ключевые слова: нитраты, вспашка, безотвальная обработка, нулевая обработка, урожайность культур, гидротермический коэффициент Селянинова (ГТК). 